Philosophy and Progress: Vols. XLIX-L, January-June, July-December, 2011 ISSN 1607-2278 (Print), DOI : http://dx.doi.org/10.3329/pp.v50i1-2.11920

\section{ON THE CONCEPT OF "FREEDOM" IN KANT'S MORAL PHILOSOPHY}

\section{Md. Abdul Muhit*}

The concept of freedom (Freiheit) plays a central role in Kant's ethical theory. Moral laws are called 'laws of freedom' on the very first page of Foundations of the Metaphysics of Morals 1 (387); and at the beginning of Section III, Kant declares a free will and a will under moral laws to be 'one and the same'. "Freedom", for Kant, "is the keystone of the whole architecture of the system of pure reason and even of speculative reason."2 Among all the ideas of pure speculative reason it is only the concept of freedom which opens up to us our means to access to the supersensible. Yet all the knowledge which it makes available to us belongs to the practical order. Above all, the concept of freedom concerns action, and especially moral action. It is "the stumbling block of all empiricists but the key to the most sublime practical principles to critical moralists, who see, through it, that they must necessarily proceed rationally." (CPrR: 7)

\footnotetext{
* Professor, Department of Philosophy, University of Dhaka

E-mail : mamuhit@hotmail.com
}

The problem of freedom appears in various perspectives and at various strata within Kant's philosophy. This paper will be devoted exclusively to what Kant says about freedom in his moral philosophy, especially in Foundations and Critique of Practical Reason. Related to the concept of freedom is the question: Is Kant a "Compatibilist" (a view which roughly holds that freedom and determinism are compatible) or an "Incompatibilist" (a view which holds that freedom and determinism are not compatible; freedom and determinism are contradictory by nature and mutually exclusive of each other so that they cannot naturally exist in a harmonious way)? This paper will also try to address this question.

\section{Freedom in the Critique of Pure Reason}

As a preliminary to our discussion of Kant's conception of freedom in his ethical works, we will first briefly give an account of what Kant thinks about freedom in the Critique of Pure Reason ${ }^{3}$. In the First Critique Kant's argument that persons are free has two stages. Here he argues that the possibility of freedom is not precluded by the nature of our experience of the world, the requirements of scientific knowledge, or any justifiable metaphysical theories. This argument depends on Kant's transcendental idealism. Kant claims that experience is structured according to two forms of intuition - space and time - and twelve categories, one of which is cause and effect. Because these intuitions and categories provide the structure of our experience, one knows a priori that any experience of ours will be spatio-temporal and will fit into a series of natural causes that are objects of possible experience. However, because these intuitions and categories structure our experience, one cannot apply them in order to know "things in 
themselves." In the context of arguing for this transcendental idealism Kant presents several antinomies, the third of which highlights the conflict between the claims that there is freedom and that there is no freedom. ${ }^{4}$ The antinomy arises because while understanding demands that every object of experience be explained in terms of a (temporally) prior cause, reason demands that this cause be sufficient, such that it leaves nothing to be explained. Only a cause that is itself not in the world can serve this purpose, because the world is structured by spatiotemporal causation such that every effect a prior cause.

Ultimately, Kant argues that the resolution of the antinomy depends on the fact that one can distinguish things as they are in themselves from things as they appear. Because experience is structured according to the laws of causality, nothing can be experienced except as determined by prior causes. Thus nothing can be experienced as free. But it is thinkable that free things in themselves provide a ground for the series of appearances that is ordered according to natural laws, and these free things neither need nor allow further explanation in terms of further causes. Because these things in themselves are not structured according to the schematized categories of human understanding, they cannot be thought of as possible objects of our experience. The way in which they "ground" appearances is at best only analogous to the way appearances ground one another. But Kant, in the Critique of Pure Reason, at least shows that nothing that one knows about natural causation rules out some sort of freedom. As he explains,

It has not even been our intention to prove the possibility of freedom. For in this also we should not have succeeded, since we cannot from mere concepts a priori know the possibility of any real ground and its causality ... What we have alone been able to show, and what we have alone been concerned to show, is that ... causality through freedom is at least not incompatible with nature. (A558/B586)

Thus in the First Critique, Kant's goal is simply to open a space for freedom. In the second stage of the argument, that is, in the Second Critique and in the Foundations Kant argues for the reality of freedom. In these two major works of his practical philosophy, Kant claims it is a "fact of reason" that people have moral obligations. Kant uses this fact "of which we become immediately conscious" to support the reality of freedom.

\section{Freedom in the Foundations of the Metaphysics of Morals}

In Section III of the Foundations Kant used the concept of freedom in explaining or clarifying the concept of autonomy. The explanation depends crucially on the distinction he made between the "negative" and "positive" concepts of freedom. Kant claims that the positive concept of freedom "flows from" the negative concept of freedom. Kant's negative characterization invites us to focus on what the free will is not, namely, determined by 'foreign causes' or by something external to itself (Foundations: 446). Kant's positive characterization draws attention to ways we can think about what the free will is, namely, Kant tells us, determined by reason.

In the Foundations, Kant offers the following "definition of freedom" as "negative" (446):

As will is a kind of causality of living beings so far as they are rational, freedom would be that property of this by which it can be effective independent of foreign causes determining 
it, just as natural necessity is the property of the causality of all nonrational beings by which they are determined to activity by the influence of foreign causes.

By 'foreign causes', Kant has in mind laws of nature. Freedom in the negative sense, for him, is a form of causality different from and independent of the causality of nature, of what he refers to here as 'natural necessity'. To be free in the "negative" sense, then, is to be independent of the laws that determine every event or happening in the realm of nature. In the Critique of Practical Reason, Kant describes "freedom in the negative sense" as "independence from all material of the law (i.e., a desired object)" in the determination of the will (CPrR: 33), and in the Metaphysics of Morals ${ }^{5}$ he writes that "freedom of choice is this independence from being determined by sensible impulses; this is the negative concept of freedom" (213). Each of these negative formulations says that a will is free if it is not compelled, determined, or necessitated by something other than itself, most often nature or natural desire.

The positive characterization, in contrast, takes us toward being able to say what free will is. Kant describes "positive freedom" as causality in accordance with immutable laws but of a special kind:

Since the concept of a causality entails that of laws according to which something (i.e., the effect) must be established through something else which we call a cause, it follows that freedom is by no means lawless even though it is not a property of the will according to laws of nature. Rather, it must be a causality of a peculiar kind according to immutable laws. Otherwise a free will would be an absurdity. (Foundations 4:446)
The positive conception of freedom makes explicit two important features of freedom. One feature is the law-governed nature of freedom. While a free act is independent of laws of nature, it is not altogether independent of law. The other feature has to do with the origin of laws of freedom. According to Kant, laws of freedom originate in the pure will. For him, when a will is heteronomously determined, it is "nature that gives law" (Foundations 4: 444). When the will is determined by laws of freedom, however, it is the pure will that gives law. To be free is to give oneself, that is, to have one's pure reason give oneself, a law. It is to have reason itself 'legislate,' or 'be practical'. When we act from laws of freedom, we bring our maxims into conformity with a law that we, as rational agents, give ourselves. Since the pure will is capable of providing a rule or law that can determine our conduct, the pure will may be said to have a kind of causality. These two features constitute Kant's "positive" concept of freedom. Adding together these two features imply that freedom of the will is nothing other than autonomy. It is nothing other than the capacity of the will of a rational being to give itself law. Freedom of the will in this positive sense is identical to autonomy because, on Kant's definition, autonomy just is "the will's property of being a law to itself' (Foundations 4: 447). Kant's identification of freedom with autonomy emphasizes the idea that a will, by virtue of its being a kind of causality, must be governed by laws (Foundations: 446).

A free will, for Kant, is an autonomous will: it is a will that not only is independent of natural necessity but can also give itself law. He claims that the law the free will gives itself is nothing other than the supreme moral law. He believes it is 
possible to establish this connection simply by analyzing the concept of a free will. Kant's reasoning relies on the following assumptions ${ }^{6}$ :

1. A will that is autonomous is a will that has the capacity to give itself law.

2. The law the autonomous or free will gives itself has its source in the faculty Kant calls the pure will, the faculty that is "nothing other than" practical reason.

3. Because the law of the free will has its source in practical reason, it is valid for all beings that possess practical reason.

4. The law that qualifies as having this kind of validity therefore commands more than merely contingent ends, ends valid for some rational natures but not others.

5. As valid for all rational natures, the law commands ends that could be willed by all rational natures. As Kant puts it, the law commands that we "act on no other maxim than that which can also have as object itself as universal law."

6. The law the free will gives itself, in other words, is the categorical imperative.

Autonomy - the property of a will to be a law to itself (Foundations: 447) - is then equated with the general formulation of the categorical imperative: the principle only to act on a maxim that 'can also have itself as a universal law as its object' (Ibid.). Kant concludes that, as this is the formula of the categorical imperative and the principle of morality, 'a free will and a will under moral laws' are identical (Ibid.).

After establishing the thesis that a will that is free and a will "under moral laws" are identical Kant proceeds on to argue for the reality of freedom. Kant gave us a first clue as to how his argument for the reality of our freedom would proceed:

I say now: every being that cannot act otherwise than under the idea of freedom is just because of that really free in a practical respect. (Foundations: 448)

Kant includes human rational wills among those that "cannot act otherwise than under the idea of freedom." $\mathrm{He}$ asserts in a passage (Foundations: 455), for example, that "[a]11 human beings think of themselves as having free will." $\mathrm{He}$ takes this to be an indisputable fact about us - a fact true even of the "most hardened scoundrel." Even the scoundrel recognizes that her actions are other than they both could and ought to be. She thus acknowledges the validity of the moral law as well as her freedom to act or not to act according to it. (Foundations: 454).

Now the question is: Even if we grant Kant's assumption that we necessarily regard ourselves as free, why should we take it to follow from this fact that we are "really free in a practical respect?" Kant's answer: We must think of ourselves as acting under the idea of freedom, because the alternative idea that we are merely biological machines is unsustainable. The conception of ourselves as nothing other than machines is inadequate, in Kant's view, if it is taken to be a sufficient account of our nature. In the paragraphs beginning at the end of Foundations: 450, Kant thus claims that we instead have to regard ourselves both as creatures determined in all that we do by natural laws and also as capable of freedom.

At this point (Foundations: 450f.) Kant introduces the idea of two standpoints. From the first standpoint, he says, we think 
of ourselves as "effects that we see before our eyes"; from the second we think of ourselves as "causes efficient a priori". The first standpoint is the "standpoint of nature; the second the "standpoint of freedom." From the "standpoint of nature" we regard ourselves as objects of nature, observable by the senses, and wholly determined by natural laws; from the "standpoint of freedom" we regard ourselves as autonomous, as endowed with the causality of practical reason by means of which we give ourselves law. From within the standpoint of nature, the standpoint Kant often refers to as the "world of sense," there is no freedom. Everything that happens is the product of antecedent causal forces. By causal forces, Kant refers to the most general laws of nature (laws of Newtonian mechanics), laws to which the special sciences such as biology, psychology, and chemistry must conform. Objects determined by these laws are objects of possible experience, or as Kant calls them, "appearances." Kant goes on to argue that when we consider human subjects as "effects that we see before our eyes," we consider them as possible objects of experience, as appearances. To consider human subjects in this way is to think of all their properties, including their actions and intentions, as caused by nature. As an appearance, or as belonging to the "world of sense," a human subject is programmed by nature to seek its own happiness or well-being; it is heteronomously determined in all that it does. It has no free will.

On the other hand, if we consider objects in abstraction from our forms of intuition, what remains, Kant tells us, are things in themselves. Although thinkable, things in themselves are outside space and time and therefore are not possible objects of experience. An example Kant frequently cites of an object that is not a possible object of experience is God. If we assume, as Kant does, that God is a being that transcends space and time, then God is not a proper object of scientific investigation. Instead, God is an object of practical knowledge or faith. Kant's analysis of the concept of free will is the same. Free will, on his account, is nowhere to be found in the realm of nature. It is not a natural or empirical property of human subjects. It belongs only to subjects conceived as members of what he now refers to as the "intellectual world" or "world of understanding." As members of the intellectual world, subjects are neither in space nor in time. As free, they possess a special, non-empirical form of causality. In Kant's terms, this special form of causality is a "pure activity" or "spontaneity" (Foundations: 452). A free will is a spontaneous form of causality in that it has the power to initiate a causal series from a standpoint outside time.

\section{Freedom in the Critique of Practical Reason}

In a footnote Kant remarks:

[T]hough freedom is certainly the ratio essendi of moral law, the latter is the ratio cognoscendi of freedom. For had not the moral law already been distinctly thought in our reason, we would never have been justified in assuming anything like freedom, even though it is not self-contradictory. But if there were no freedom, the moral law would never have been encountered in us. (CPrR: 4)

Kant maintains that pure practical laws have their foundation in "the concept of their existence in the intelligible world, i.e., freedom ... For this concept has no other meaning, 
and these laws are possible only in relation to the freedom of the will." (CPrR: 46) Apart from freedom the moral law would be a mere deception of our reason. Without it "no moral law and no accountability to it are possible." (CPrR: 97) Put another way, apart from freedom, the moral law "would never have been encountered in us", for freedom is the ratio essendi of moral law, which causes it to be. We know the possibility of freedom a priori; it is the condition of the moral law.

Thus, in order of existence, freedom is prior to the moral law, as its ratio essendi. But in order of knowledge, the moral law comes first: it is the ratio cognoscendi of freedom. "It is therefore the moral law, of which we become immediately conscious ... which leads directly to the concept of freedom." (CPrR: 29-30) That we are conscious of the moral law is an indisputable fact attested by the common conscience. "The moral law is given, as an apodictically certain fact, as it were, or pure reason, a fact of which we are a priori conscious." (CPrR: 47) The apodictic certainty attached to the fact guarantees the objective reality of the moral law.

According to Kant, the moral law is a fact of reason - that is, rather than arising from a deduction from previously established truths, it is given to us as an original datum, which we cannot go beyond. Properly speaking, it is an absolute principle from which other data can doubtless be deduced but which is not itself derived through any process of reasoning. Our certainty about moral law is thus immediate, rather than discursive. This moral law which requires no deduction and no "justifying grounds", serves itself as a principle of the deduction of the power of freedom, which it "shows to be not only possible but actual in beings which acknowledge the law as binding upon them." (CPrR: 47) Freedom is deduced from the moral law; it is the object of a demonstration. Therefore, it is discursively certain and cannot be likened to the moral law as a fact of reason.

However, for Kant, freedom cannot be demonstrated directly, but indirectly through a mediating principle. We are conscious of freedom through the mediation of moral law; but the movement from the moral law to freedom is immediate: the moral law leads "directly to the concept of freedom." (CPrR: 30) The moral law is freedom's unique and irreplaceable credential. Only the moral law could authorize us to view ourselves as "compelled" to assume the existence of freedom. As Kant remarks: "[N]o one would dare introduce freedom into science had not the moral law and, with it, practical reason come and forced this concept upon us." (Ibid.) "...had not the moral law already been distinctly thought in our reason, we would never have been justified in assuming anything like freedom, even though it is not self-contradictory." $\left(C \operatorname{PrR}: 4_{\mathrm{n}}\right)$ Apart from freedom, the moral law would never have been discovered in us; but apart from the moral law, freedom would have remained completely unknown. Thus the two concepts "reciprocally imply each other." (CPrR: 29)

It is Kant's contention that a theoretical proof that a rational being is free is impossible for the human reason. To establish freedom theoretically would be to achieve knowledge of the noumenal world but that is something that we cannot have. But although we cannot give a theoretical proof of freedom it does not mean that the idea of freedom is a mere fiction in any ordinary sense. For Kant, we cannot act morally, for the sake of duty, except under the idea of freedom. 
Obligation "ought" implies freedom - freedom to obey or disobey the law. Nor can we regard ourselves as making universal laws, as morally autonomous, save under the idea of freedom. The will of a rational being must regard itself as free. As Kant remarks in the Foundations: "I affirm that we must necessarily grant that every rational being who has a will also has the Idea of freedom and that it acts only under this Idea. For in such a being we think of a reason which is practical." (448) The idea of freedom is thus practically necessary. And the practical necessity of the idea of freedom involves, for Kant, our regarding ourselves as belonging, not only to the world of sense, the world governed by determined causality, but also to the noumenal or intelligible world. Man can regard himself from two standpoints: as belonging to the world of sense he finds himself to natural laws; as belonging to intelligible world, he finds himself under laws which have their foundation in reason alone.

In granting that man be regarded from two points of view Kant seems to involve himself in a difficult position. As there is no faculty of intellectual intuition, we cannot observe actions which belongs to the noumenal sphere; all the actions which we can observe belong to the world of sense. That is to say, they are all given in time and subject to the laws of causality. We cannot, therefore, make a distinction between two types of experienced actions, saying that these are free while those are determined. If, then, we assume that man, as a rational being, is free we are compelled to hold that the same actions can be both determined and free.

Kant, however, is well aware of this difficulty. He maintains that if we wish to save freedom "no other course remains than to ascribe the existence of a thing so far as it is determinable in time and accordingly its causality under the law of natural necessity, merely to appearance, and to attribute freedom to the same being as a thing-in-itself." (CPrR: 95) And he then asks: How can a man be completely free at the same moment and in regard to the same action in which he is subject to an inevitable natural necessity? As in Foundations (450f) Kant in the second Critique provides the answer in terms of temporal conditions. In so far as a man's existence is subject to temporal conditions his actions form part of the mechanical system of nature and are determined by antecedent causes. In Kant's own words: "But the same subject, which, on the other hand, is conscious also of his own existence as a thing-in-itself, also views his existence so far as it does not stand under temporal conditions, and himself as determinable only by laws which he gives to himself through reason." (CPrR: 97) And to be determinable only through self-imposed laws is to be free.

It may be mentioned here that the statement that man is noumenally free and phenomenally determined in regard to the very same actions is a "hard saying. But it is one, which given his premises, Kant cannot avoid."’

In the Critique of Practical Reason we find that freedom occupies a privileged place among the ideas of pure reason. "Freedom ... among all the ideas of speculative reason is the only one whose possibility we know a priori. We do not understand it, but we know it as the condition of the moral law which we do know." (CPrR: 4) By contrast, we neither know nor understand the possibility and the reality of God and immortality, since they are not conditions of the moral law but merely conditions of the highest good, which is the necessary 
object of a free will. "Through the concept of freedom, the ideas of God and immortality gain objective reality and legitimacy." (Ibid.) Evidently this privilege decisively sanctions the priority of freedom over the other ideas. Following the proof of the objective reality of freedom we penetrated the intelligible world and glimpsed the possibility of further knowledge of the supersensible order. "It is, properly speaking, only the concept of freedom, among all the ideas of pure speculative reason, which brings such a great extension in the field of the supersensible, though it is only practical knowledge which is enlarged." (CPrR: 103)

It is important to note here that the deduction of God and immortality is not accomplished directly from the moral law but only with the intervention of freedom. "All other concepts (those of God and immortality) which, as mere ideas, are unsupported by anything in speculative reason now attach themselves to the concept of freedom and gain, with it and through it, stability and objective reality. That is, their possibility is proved by the fact that there really is freedom, for this Idea is revealed by the moral law." (CPrR: 3-4) The moral law leads directly to freedom, but we have no direct consciousness of God and immortality. "Only the concept of freedom enabled us to find the unconditioned for the conditioned and the intelligible for the sensuous without going outside ourselves." (CPrR: 105)

\section{Is Kant a compatibilist or an incompatibilist?}

Before we attempt to answer this question we first need to clear up the terminological issues involving "compatibilism" and "Incompatibilism." By "compatibilism" we traditionally mean that freedom and determinism are compatible in the sense that although human actions are determined, they can also be free for moral imputation. This means freedom and determinism do not fundamentally disagree with each other so that they can naturally exist harmoniously in human actions. By "incompatibilism" we traditionally mean that if determinism is true then freedom, hence moral responsibility, is an illusion. This means that freedom and determinism are contradictory by nature and mutually exclusive of each other so that they cannot naturally exist in a harmonious way. Now the question is: What is Kant: a compatibilist or an incompatibilist? On the one hand, Kant thinks that freedom and determinism are two separate causalities belonging to two different worlds, namely, noumenal and phenomenal worlds, and following two different laws, which makes him an incompatibilist; on the other hand, Kant thinks that he has reconciled them by making the effects of noumena part of phenomena determined by the universal law of nature and making them not conflict with one another in the same action, which makes him a compatibilist. So, is Kant both a compatibilist and an incompatibilist? It is not easy to give a straightforward answer to this question. On some readings Kant seems to lean on compatibilist camp while on other readings he seems to be an incompatibilist. Let us look into the issue in more detail.

Incompatibilist Freedom: Kant's philosophy, including his ethics, takes noumena and freedom as primary and phenomena and determinism as merely secondary. His belief in the primacy of freedom is reflected in the following two well-quoted lines:

The concept of freedom, in so far as its reality is proved by an apodictic law of practical reason, is the keystone of the 
whole architecture of the system of pure reason and even of speculative reason. (CPrR: 3 )

The concept of freedom is the stumbling block of all empiricists but the key to the most sublime principles for critical moralists, who see, through it, that they must necessarily proceed rationally. (CPrR: 7)

Kant wanted to reconcile freedom and nature by making freedom the primary causality and nature only the secondary causality grounded in freedom. But the belief in the priority of freedom precludes any straightforward compatibilism. Like compatibilists, Kant holds that human actions are both causally predetermined and free. But unlike most compatibilists - socalled "soft determinists" - Kant insists that the free cause of one's actions cannot be predetermined. Whereas soft determinists interpret "freedom" in such a way that a free cause can be determined by prior natural causes, Kant affirms that people are free causes of their actions, and that those actions are determined by an infinite series of natural causes, but also that a free cause cannot itself be causally determined. Kant is adamant about the insufficiency of standard compatibilist accounts of freedom as grounds for moral imputation. In the Critique of Practical Reason, Kant clearly expresses his dissatisfaction with "soft determinist" accounts of freedom. If such an account were true, Kant says,

Man would be a marionette or an automaton . . . fabricated and wound up by the Supreme Artist; . . . self-consciousness would indeed make him a thinking automation, but the consciousness of his spontaneity, if this is held to be freedom, would be a mere illusion. (101)
Freedom that has its ultimate cause in anything else, whether this is a natural world or divine Creator, is not real freedom but "mere illusion." And this soft determinist freedom is simply not enough to provide a condition of the possibility of moral responsibility, as Kant makes clear elsewhere in the second Critique:

It is a wretched subterfuge to seek an escape in the supposition that the kind of determining grounds of his [man's] causality according to natural law agrees with a comparative concept of freedom. According to this concept, what is sometimes called "free effects" is that of which the determining natural cause is internal to the acting thing. For example, that which a projectile performs when it is in free motion is called by the name "freedom" because it is not pushed by anything external while it is in flight. (95-96)

A few sentences later, Kant explains why he believes that this compatibilist solution is unacceptable:

They therefore leave no room for transcendental freedom, which must be thought as independence from everything empirical and hence from nature generally ...; without this transcendental freedom in its proper meaning, which is alone a priori practical, no moral law and no accountability to it are possible.(CPrR: 96-97)

Kant seems to believe that a compatibilist account of freedom does not leave room for the freedom necessary for moral responsibility. If one is to be held morally responsible for an action, it must be possible to be free of empirical determination, because this sort of autonomy is morally required. If forces of nature ultimately cause all action, the best that anyone can hope for is action in conformity with the 
demands of the moral law. One could never act from the moral law itself, because the moral law is not a force of nature. And acting from the moral law is precisely what the moral law demands.

Compatabilist Freedom: For Allen Wood ${ }^{8}$, Kant is basically a compatibilist, although for him "Kant's compatibilism is of a most unusual sort" in that "freedom and determinism are compatible only because the self as free moral agent belongs to different world from that of the self as natural object". (1984: 75) Kant's reconciliation of freedom and nature lies in his metaphysical division of appearances and things in themselves and of intelligible character and empirical character. This point is clearly spelled out by Kant first in the Foundations, and later on in the Critique of Practical Reason. Thus in the Foundations Kant remarks:

[A] rational being must regard itself qua intelligence ... as belonging to the world of understanding and not to that of the senses. Thus it has two standpoints from which it can consider itself and recognize the laws [governing] the employment of its powers and all its actions: first, as belonging to the world of sense, under the laws of nature (heteronomy), and, second, as belonging to the intelligible world under laws which, independent of nature, are not empirical but founded on reason alone. (452)

In the Critique of Practical Reason Kant argues:

The determination of the causality of being in the world of sense as such can never be unconditioned, and yet for every series of conditions there must be something unconditioned, and consequently a causality which is entirely selfdetermining ... But because it is absolutely impossible to give an example of it from experience, since no absolutely unconditioned determination of causality can be found among the causes of things as appearances, we could defend the supposition of a freely acting cause when applied to a being in the world of sense only in so far as that being was regarded also as noumenon. This defense was made by showing that it was not self-contradictory to regard all its actions as physically conditioned so far as they are appearances, and yet at the same time to regard their causality as physically unconditioned so far as the acting being is regarded as a being of the understanding ... I thereby do not indeed learn what the object may be to which this kind of causality is attributed. I do, however, remove the difficulty, since, on the one hand, ... I leave to the mechanism of natural necessity ... while, on the other hand, I hold open for speculative reason the place for which it is vacant, i.e., the intelligible ... Pure practical reason now fills this vacant place with a definite law of causality in an intelligible world (causality through freedom), namely the moral law. (48-49)

Wood summarizes Kant's point thus:

As effects of our empirical character, our actions are necessitated by natural causes and hence unfree. But as effects of our intelligible character, it is possible that the same actions are produced by a transcendentally free cause, which is not necessitated by anything sensuous and is capable of autonomous or a priori volition." (1984: 85)

From the above analysis it appears that Kant is neither a compatibilist nor an incomatibilist in the strict senses of the terms. In so far as Kant's avowed purpose is to unite nature and freedom in order to remove the apparent contradiction between the mechanism of nature and freedom and to show that causality from freedom does not contradict nature his position 
comes close to compatibilism. On the other hand, when Kant's solution to reconcile freedom and nature involves making freedom the primary causality and nature only the secondary causality grounded in freedom his position appears to be an incompatibilist position. This might be the reason Allen Wood, in his famous article "Kant's Compatibilism", comments that Kant's views "do not fit neatly into the customary pigeonholes", and, therefore, Wood terms Kant's position as "the compatibility of compatibilism and incompatibilism."

\section{Conclusion}

Notwithstanding the place of privilege which freedom enjoys among the ideas of pure reason, it remains mysterious in many respects. The idea of freedom is incomprehensible and impenetrable. It is "the transcendental predicate of a causality of a being which belongs to the world of sense." (CPrR: 94) It does not itself belong to the sensuous. The ground of freedom is "inscrutable" - it is a mystery because this ground is not given to us as an object of knowledge. However, although mysterious, Kant's attempt to solve the problem of freedom is ground-breaking in that Kant at least has separated freedom from the dominance of determinism.

\section{Notes and References}

1 Grundlegung zur Metaphysik der Sitten (1785); translated by Lewis White Beck as Foundations of the Metaphysics of Morals (New Jersey: Prentice-Hall, Inc., 1997). All references to this work are identified by Foundations with pagination from the Royal Prussian Academy edition and are taken from Beck's translation.

2 Immanuel Kant, Kritik der praktischen Vernunft (1788); translated by Lewis White Beck as Critique of Practical Reason, 3rd ed., (New Jersey: Prentice-Hall, Inc., 1993): 4. Kant's Critique of Practical Reason is also known as the Second Critique. Quotations from this work are identified by $C P r R$ with pagination from the Royal Prussian Academy edition and are taken from Beck's translation.

3 Kritik der reinen Vernunft $(1781,1787)$; translated by N. Kemp Smith as Immanuel Kant's Critique of Pure Reason (London, Macmillan \& Co. Ltd, 1950). Critique of Pure Reason is also popularly known as the First Critique. All references to this work are given in the traditional way, by citing the page numbers in ' $\mathrm{A}$ ' and/or 'B' editions.

4 In the First Critique Kant argues that the antinomy is between a thesis that "causality in accordance with laws of nature is not the only causality from which the appearances of the world can one and all be described. To explain these appearances it is necessary to assume that there is another causality, that of freedom" and an antithesis that claims that "there is no freedom; everything in the world takes place solely in accordance with laws of nature" (A444-5/B472-3).

5 Metaphysik der Sitten (1797); translated by Mary Gregor as The Metaphysics of Morals (Cambridge: Cambridge University Press, 1991). All references to this work are given from the Royal Prussian Academy edition and are taken from Mary Gregor's translation.

6 See Sedgwick, Sally, Kant's Groundwork of the Metaphysics of Morals: An Introduction, Cambridge: Cambridge University Press, 2008. p.171

7 Copleston, F. A History of Philosophy, v. VI, (The Newman Press, 1962); p. 336

8 Wood, Allen. "Kant's Compatibilism", Self and Nature in Kant's Philosophy, edited by Allen Wood. Ithaca: New York, 1984: 73101. 